\title{
Injection Therapy for Enthesopathies Causing Axial Spine Pain And "The Failed Back Syndrome:" A Single Blinded, Randomized ANd CROSS-Over Study
}

\begin{abstract}
Harold A. Wilkinson, MD, PhD
Background: Enthesopathies are a common cause of axial pain that is amenable to "minimally invasive" therapy.

Objective: To evaluate the effectiveness of injection therapy for enthesopathies.

Design: Single blinded, randomized, and cross-over study.

Methods: Thirty-five patients diagnosed as having painful enthesopathies as a major pain generator were studied. Of the patients studied, $86 \%$ of patients had undergone prior lumbar spine surgery and all were referred for neurosurgical evaluation for possible surgery. Patients were injected either with anesthetics alone or with anesthetics combined with phenol-glycerol proliferant prolotherapy. Outcomes were analyzed both clinically at the time of regular follow-ups, and by a series of multipart questionnaires.

Results: Patients received a total of 86 injections, 39 with local anesthetics, and 47 with prolotherapy. By clinical assessment

patients obtained excellent to good relief of pain and tenderness after $80 \%$ of prolotherapy injections, but only $47 \%$ after anesthetics alone. By questionnaire, $66 \%$ reported excellent to good relief after prolotherapy vs. $34 \%$ after anesthetics alone. Patients reported improvement in work capacity and social functioning following both types of injections, but a greater reduction in focal pain intensity following prolotherapy injections. The mean and median durations of persistent relief were 2.4 and 1.75 months with prolotherapy vs. 1.8 and 0.75 months with anesthetics alone. Roughly $10 \%$ obtained greater than six months of relief from either injection. In the crossover portion of the study, patients reported that prolotherapy injections following initial anesthetic-only injections provided much better relief than that achieved after their anesthetic-only injections, and that anesthetic-only injections following initial prolotherapy injections failed to provide relief as
\end{abstract}

"Minimally invasive" approaches to therapy have become a major goal in current health care delivery. For many years, osteopathic physicians have recognized that painful enthesopathies can be clinically significant, major pain generators and are a common cause of persistent axial or spine pain which responds to "minimally invasive" office based injec-

From: Harold A. Wilkinson, MD, PhD, Wellesley Hills, MA

Address Correspondence:

Harold A. Wilkinson, MD, PhD

5 Rockridge Road

Wellesley Hills, MA 02481-1432

Disclaimer: There was no external funding in preparation of this manuscript.

Conflict of Interest: None

Acknowledgement:

Manuscript received on 11/15/2004

Revision submitted on $12 / 29 / 2004$

Accepted for publication on $3 / 5 / 2005$ good as that achieved after their prolotherapy. Subsequent to this study, only four of 35 patients required additional spine surgery, but 29 of the 35 patients requested additional injections.

Conclusions: Injection therapy of pain ful enthesopathies can provide significant relief of axial pain and tenderness combined with functional improvement, even in "failed back syndrome" patients. Phenol-glycerol prolotherapy provides better and longer lasting relief than injection with anesthetics alone. Prolotherapy provides over six months of relief for some patients but generally provides relief for only a few months. However, most patients described good to excellent relief, felt that the injections had been beneficial, and requested additional injections for recurrent or residual focal pain.

Keywords: Enthesopathies, prolotherapy, phenol/glycerol solution, spine pain, failed back syndrome tion therapy. Enthesopathies are defined in Dorland's Medical Dictionary as "disorders of the muscular or tendinous attachments to bone" (1) and are also referred to as periosteal or fibroosseous junction trigger points (which differ significantly from muscular trigger points). An increasing number of allopathic orthopedists, interventional pain physicians, and physiatrists are becoming aware of this entity and its treatment (2-22). The author, a neurosurgeon, was introduced to diagnosis and treatment of these conditions by injection therapy several decades ago and continues to find it useful in his practice (23) despite the scarcity of good scientific data quantitating its effectiveness and the optimal formulation of the injectate.

Prolotherapy, or sclerotherapy, is a form of injection therapy which seems to be especially suitable for treating en- thesopathies. Prolotherapy aims to reduce pain in part by toughening tissues through chemomodulation, mediated by cytokines and multiple growth factors, to induce fibroblast proliferation and secondary deposition of collagen fibers, and in part through chemoneuromodulation of peripheral nociceptors $(2,8,9,12,14$, $17-19,24,34)$. It traces its roots to the technique used by Hippocrates to treat chronic shoulder subluxation through the insertion of red hot wires into the shoulder (27). It is similar in concept to the collagen modulating electrothermal techniques that are currently being used for tightening damaged shoulder capsules or intervertebral discs (intradiscal electrothermal techniques). Its modern day evolution began in the 1930s with the studies of Hackett and others $(25,27)$, and is now widely practiced and discussed in many 
pain management, neurosurgical, and orthopedic texts $(4,5,7,8,11,16,20,21,23$, 35-40). A variety of different sclerosing, neuromodulating and/or hyperosmolar solutions have been used for prolotherapy. Phenol-glycerol prolotherapy is weakly hyperosmolar and probably also helps to reduce pain in tender areas through the deactivation of unmyelinated small " $\mathrm{C}$ " nerve fibers (41).
Many studies of prolotherapy have been published, but few of them have been blinded and rigorously carried out in a scientific fashion $(4,8,9,12,14,15$, $17,18,23,25,26,31-34)$. This study entails careful, quantitative observations by a neurosurgeon with extensive experience both in the surgical management of pain and in dealing with patients with "the failed back syndrome.” It is a single blind- ed, randomized, and crossover study comparing phenol-glycerol prolotherapy with local anesthetic injection only (Fig. 1). Local anesthetics were chosen as the control injection because there are published comments suggesting that injecting painful enthesopathies simply with local anesthetics can provide equally good outcomes $(17,18,42)$. The injections in this study were all into enthesopathies at the

\section{Flow Diagram for Randomized Trial}

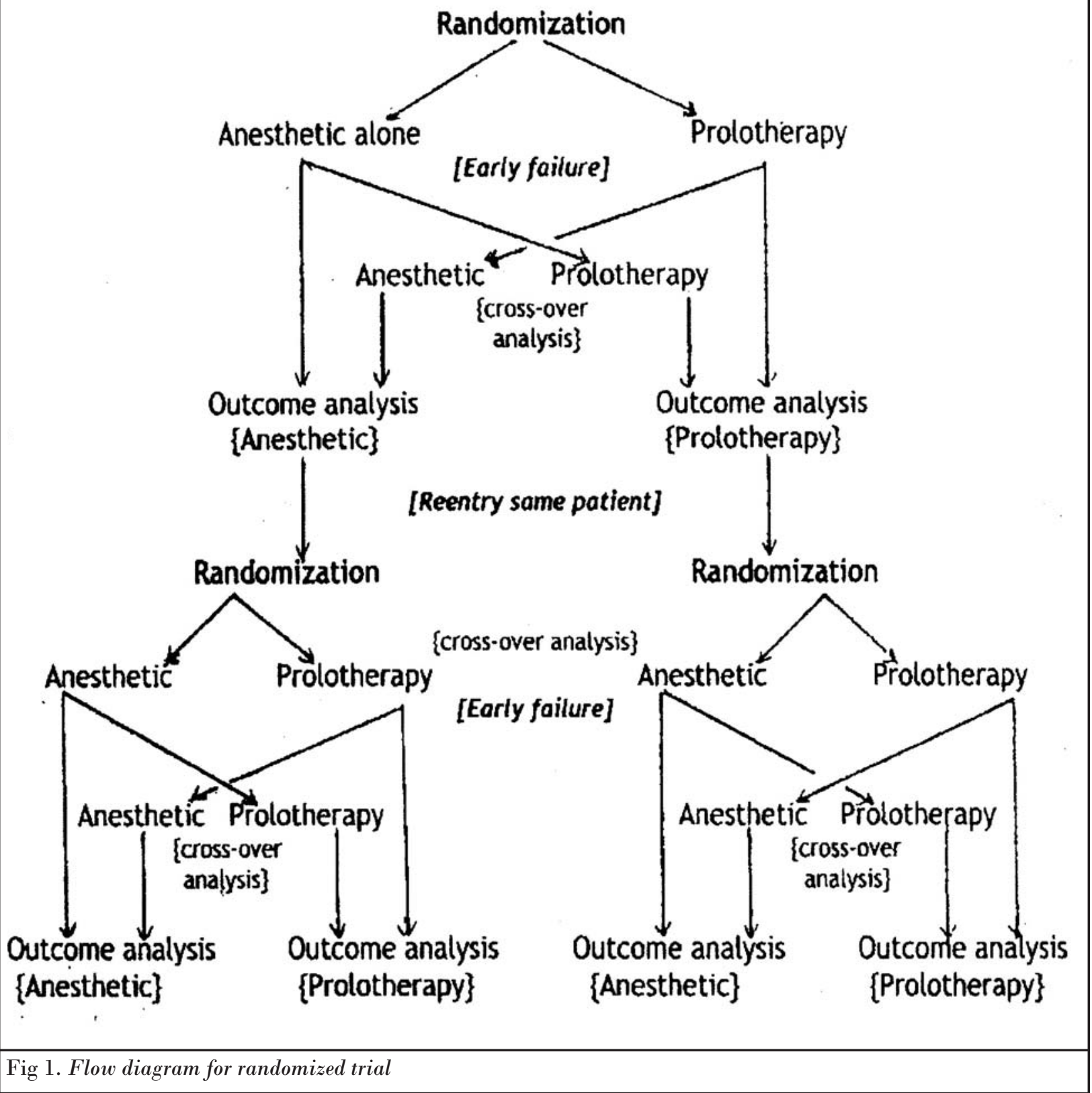


fibroosseous, periosteal interface, not into muscular trigger points.

\section{Methods}

This study was conducted at the author's private practice, and thus, approv-

Table 1. Patient demographics

\begin{tabular}{|c|c|c|c|c|}
\hline & Prolotherapy & Anesthesia & All Patients \\
\hline \multicolumn{2}{|c|}{ Number of Patients (1) } & 30 & 26 & 35 \\
\hline \multicolumn{2}{|c|}{ Average Age (Range) } & $50(24-73)$ & $47(24-73)$ & $50(24-73)$ \\
\hline \multirow{2}{*}{ Gender: } & Male & $12(40 \%)$ & $10(38 \%)$ & $14(40 \%)$ \\
\hline & Female & $18(60 \%)$ & $16(62 \%)$ & $21(60 \%)$ \\
\hline \multicolumn{5}{|c|}{ Enthesopathy Location: } \\
\hline \multicolumn{2}{|c|}{ Posterior Pelvis (2) } & $24(80 \%)$ & $21(81 \%)$ & $27(77 \%)$ \\
\hline \multicolumn{2}{|c|}{ Other Spinal } & $6(20 \%)$ & $5(19 \%)$ & $8(23 \%)$ \\
\hline \multicolumn{2}{|c|}{ Prior Back Operation } & $26(87 \%)$ & $23(88 \%)$ & $30(86 \%)$ \\
\hline
\end{tabular}

(1) Most patients received more than one injection, and 21 received injections of both types (2) $84 \%$ of those with prior back operations had posterior pelvic enthesopathies



Fig 2. Painful enthesopathies should be injected in the center of the area of maximum tenderness and in the surrounding tender area in a three dimensional configuration. Maximum tenderness is usually encountered at the fibroosseous junction adjacent to periosteum. surgical operative intervention. As a major component of their clinical picture, their complaints included both axial pain (i.e., pain in, or adjacent to, the spine) and localized tenderness as a major component of their clinical picture, although in addition many suffered from radicular symptoms or symptoms suggesting other spinal disorders. Painful enthesopathies were further defined in this study as persistent focal fibroosseous or periosteal areas of marked and focal tenderness, with no underlying bony pathology, emanating pain during inactivity and on motion. Preliminary diagnosis was made by history and palpation. Nice et al (30) demonstrated that specific training greatly improves intertester diagnostic reliability. The diagnosis was confirmed by eliminating most of the tenderness and pain from that area by anesthetic injection.

Thirty-five patients were entered in the study, 14 male and 21 female (Table 1). Their ages ranged from 24 to 73 years and averaged 50 years. Thirty of the 35 patients $(86 \%)$ had undergone prior lumbar spine operations but still complained of severe axial pain and disability and were referred as "failed back syndrome" patients. Before entering this study all patients had the diagnosis of a painful enthesopathy confirmed by at least one prior anesthetic injection at the same site (16 of the prior injections also included corticosteroids and 25 injections included prolotherapy). Twenty-seven of the enthesopathies were located at the posterior iliac crest $(77 \%)$ and the other eight were located elsewhere along the spine (lumbar1 , thoracic-6, cervical-1).

Initial injections were randomized (using a table of random numbers in units of 10) between injection with anesthetics alone vs. injections with anesthetics then phenol-glycerol prolotherapy (Fig. 1). In all patients the entire tender periosteal area was initially infiltrated (Fig. 2) with $1 \%$ lidocaine without epinephrine, usually a $10 \mathrm{ml}$ volume depending on the size of the enthesopathy, then patients were immediately tested to ensure that most if not all of the focal tenderness had been relieved. Patients randomized to the anesthetics alone group received subsequent infiltrations in the same area with an equal volume of $0.5 \%$ bupivacaine without epinephrine. Patients randomized to the prolotherapy group received infiltrations subsequent to the lidocaine with an equal volume of a mixture of the $0.5 \%$ bu- 
pivacaine which also contained $1 \%$ phenol and 10\% glycerol. (A solution containing $10 \%$ phenol in anhydrous glycerol was prepared by a pharmacy; $1 \mathrm{ml}$ of this solution was mixed with $9 \mathrm{ml}$ of $0.5 \%$ bupivacaine by the operator prior to injection.) Immediately following injection all patients were questioned about the degree of relief of pain achieved, spontaneously and on motion. Injection was considered adequate if nearly all of the local tenderness and most of the spontaneous pain from that area had been eliminated.

The degree of benefit provided by each injection was characterized as "Excellent," "Good," "Partial," or "Poor," based on reduction of pain and tenderness at the injected site. Patients reporting "Excellent" or "Good" relief of pain reported a reduction in analog pain scores (scale $0-10$ ) to 3 or less at the injected site. Since painful and tender enthesopathies are encountered in patients with other pain generating abnormalities, patients in whom the enthesopathy was found to be their chief pain generator were designated as having achieved "Excellent" outcomes, while those with persistent pain or disability from other causes (but with good relief at the injected site) were designated as having achieved "Good" outcomes. Patients who reported "Partial relief" continued to report analog pain scores of 4-6 at the injected site, but nonetheless felt that the injection had been beneficial to them. Most of them requested repeat injections when the focal pain and tenderness persisted or again became more severe. $\mathrm{Pa}$ tients who reported "Poor relief" obtained no useful relief of pain subjectively or objectivity, so that they did not request, or declined, repeat injections. The duration of relief obtained was defined either as the maximum duration of relief until the time of pain recurrence or the longest time of follow-up during which relief was maintained, thus underestimating the actual duration of relief for some patients.

Crossover results were obtained in one of two ways (Fig. 1). Patients who felt that they had not obtained adequate relief of pain and tenderness within seven to 14 days following injection were given the option to request a blinded second injection of "the other solution." They were told only that the second injection was "the other solution" and not the blinded solution which they had first received. Crossover results also were obtained when patients returned after more than six weeks and requested a repeat injection as a continuation of their participation in the study. These injections were again randomized, so that some patients received a repeat of the same injection and others received the alternate solution.

An assessment of clinical results was made by examining and questioning patients at the time of their regularly scheduled follow-up office visits. In addition patients were given written report forms. An initial questionnaire was filled out by patients prior to receiving their first blinded injection and before each subsequent blinded injection. Patients were asked to mail in post injection forms one week after their injection and then each month following the injection. Each report form contained questions regarding the current status of: (A) the severity of both their pain and their tenderness (on a 0 -10 analog pain scale) at the injected site and their overall pain burden; (B) their medication usage; $(C)$ their activities of daily living; (D) their ability to work or to carry out their normal routine; (E) the severity of impairment of their social activities which they ascribed to their enthesopathy and also to their overall pain burden; and (F) how beneficial they felt their injection had been to them.

Statistical significance was determined by calculating $\mathrm{P}$ values using the Wilcoxon Rank Sum Test.

\section{REsULTS}

Thirty-five patients received a total of 86 injections, 39 with local anesthetics alone and 47 with prolotherapy. This included 17 alternate injections which were given at the patients' request because of a perceived lack of benefit from the first injection. Twelve alternate injections were given after a first injection with anesthetics alone and five were given after a first injection which included prolotherapy. This accounts for the larger number of prolotherapy injections and also is an indication of the better results achieved with prolotherapy injections than with injections of anesthetics alone.

Based on clinical assessment, patients who were injected with anesthetics alone reported excellent or good results from $47 \%$ of injections and poor results from $45 \%$ (one patient was lost to follow-up after one of his injections). In contrast, patients who were injected with prolotherapy reported excellent or good results from $80 \%$ of injections, and reported poor results from only $11 \%$ (two injections were lost to follow-up). This difference is statistically significant (Table 2). Excellent or good benefit following injection of anesthetics alone lasted a mean of 1.8 months with a median duration of only 0.75 months. Three patients $(8 \%)$ were still enjoying excellent or good relief when last seen eight to 12 months after their anesthetic injections, and four patients (10\%) enjoyed sustained relief of greater than six months. Patients injected with prolotherapy reported a statistically significantly greater mean duration of excellent or good results (2.4 months) with a median duration of 1.75 months. Five patients $(11 \%)$ were still enjoying excellent or good relief when last seen three to 12 months after their prolotherapy injections. Only five patients (11\%) were known to be still enjoying excellent or good relief more than six months following injection - nearly the same percentage as those injected with anesthetics alone. There were no significant complications.

A quantification of benefit obtained from each of the two types of injections based on patients' self report by questionnaire differs somewhat from the clinical assessment of benefit. (Possible variables responsible for the difference include the variable intervals between injections and clinical evaluations versus the fixed intervals between injections and reports, and also that a number of patient reports were incomplete.) Patients reported that injection with anesthetics alone provided excellent or good results in only $34 \%$ of injections but poor results in $21 \%$ - with a greater number reporting partial relief (45\%). In contrast, those injected with prolotherapy reported excellent or good results from $66 \%$ of injections, and remarkably only $6 \%$ reported poor results. This is again statistically significant (Table 2).

An analysis of questionnaires which patients completed showed that the baseline status of patients was quite similar for both injection groups (Table 3). Patients reported a statistically significant improvement in work capacity and social activities following both injections, with a greater reduction in focal pain intensity following prolotherapy injection as compared to injection of anesthetics alone. Many patients continued to require medications and to suffer functional impair- 
Table 2. Assessments of benefit from injections

\begin{tabular}{|l|c|c|c|}
\hline & Prolotherapy & Anesthetic alone & Comparison \\
\hline & $\begin{array}{c}\text { Number or } \\
\text { Mean } \pm \text { SD }\end{array}$ & $\begin{array}{c}\text { Number } \\
\text { Mean } \pm \text { SD }\end{array}$ & P Value (1) \\
\hline $\begin{array}{l}\text { Clinical Assessment } \\
\text { Number of injections with: }\end{array}$ & \\
\hline Good/Excellent benefit & 36 of $45(80 \%)$ & 18 of $38(47 \%)$ & NA \\
\hline Poor benefit & 5 of $45(11 \%)$ & 17 of $38(45 \%)$ & NA \\
\hline Degree of benefit (2) & $2.3 \pm 1.0$ & $1.3 \pm 1.3$ & 0.0001 \\
\hline Duration of benefit (mos.) & $2.4 \pm 2.8$ & $1.8 \pm 3.1$ & 0.01 \\
\hline Patient Reported (3) & & & \\
\hline Number of injections with: & 23 of $35(66 \%)$ & 10 of $29(34 \%)$ & NA \\
\hline Good/Excellent benefit & 2 of $35(6 \%)$ & 6 of $29(21 \%)$ & NA \\
\hline Poor benefit & $2.6 \pm 1.1$ & $1.8 \pm 1.2$ & 0.005 \\
\hline Degree of benefit & & & \\
\hline
\end{tabular}

(1) Wilcoxon rank sum test

(3) Not all patient reports were complete

ment due to other painful, or functionally limiting, components of their complex problems.

Thirty-five pairs of injections were available for analysis in the crossover portion of the study (Table 4). More patients received prolotherapy injections following initial anesthetic injection because 12 patients requested an alternate injection for perceived failure to obtain satisfactory relief following initial injection with anesthetics only. Only five patients requested an alternate injection following initial injection with prolotherapy. Prolotherapy subsequent to an initial prolotherapy injection, and anesthetics alone subsequent to an initial anesthetic injection, both provided slightly better, but not statistically significant, cumulative benefit (using a scale of 0 to 3 , with 3 representing excellent benefit). The benefit reported to have resulted from each set of prolother- apy injections (initial injection and subsequent injection) was significantly better statistically than the results reported from anesthetic injections (benefit scores $=2.3$ and 2.5 for prolotherapy vs. benefit scores $=1.1$ and 1.5 for anesthetics alone). Results from anesthetic injections subsequent to an initial prolotherapy injection were much inferior to those achieved after the prolotherapy injection (change in average benefit score $=-0.8$ ). In contrast results from prolotherapy injections subsequent to an initial anesthetic injection were strikingly and significantly more beneficial statistically (improvement in average benefit score $=+1.4$ ).

As noted earlier, 30 of the 35 patients had been referred because of continuing pain and disability despite prior lumbar spine surgery; they were referred as "failed back syndrome" patients for neurosurgical evaluation and possible addi- tional spine surgery. After the conclusion of this study only four patients required repeat surgical intervention. However, 29 of the 35 patients subsequently requested additional trigger point injections for residual or recurrent axial spine pain and tenderness.

\section{DISCUSSION}

Some skepticism has been expressed in the literature regarding the clinical significance and the effectiveness and appropriateness of prolotherapy $(6,43,44)$. Former United States Surgeon General C. Everett Koop explains this reluctance to accept prolotherapy of myofascial pain as follows: "Medical folks are skeptical, and prolotherapy, unless they have tried it and proven its worth, seems to be too easy a solution to a series of complicated problems that afflict the human body and have been notoriously difficult to treat by any other method (44)."

Painful enthesopathies differ significantly from muscular trigger points both in anatomic location and pathology, though little histologic evidence is available for either condition $(21,23,31,33$, $37,45)$. Both occur commonly in situations of muscular weakness and ligamentous laxity, especially when muscle tension is heightened by anxiety or depression, but both can develop in otherwise healthy individuals following extreme or unexpected effort. Many patients develop painful enthesopathies while recovering from lumbar disc disease and spinal surgery when they resume physical exertion after prolonged periods of inactivity.

Repeated injections of corticoste-

Table 3: Data submitted by patients in written reports (by injection type before and after each injection)

\begin{tabular}{|c|c|c|c|c|c|c|c|c|c|}
\hline & \multirow{4}{*}{ Scale } & \multirow{2}{*}{\multicolumn{2}{|c|}{$\begin{array}{l}\text { Status Before } \\
\text { Injection }\end{array}$}} & \multirow{2}{*}{\multicolumn{2}{|c|}{$\begin{array}{c}\text { Maximum Benefit } \\
\text { Post Injection }\end{array}$}} & \multicolumn{4}{|c|}{ Comparative P values (Wilcoxon) } \\
\hline & & & & & & \multirow{2}{*}{\multicolumn{2}{|c|}{$\begin{array}{l}\text { Comparison of } \\
\text { Baseline Values }\end{array}$}} & \multirow{2}{*}{\multicolumn{2}{|c|}{$\begin{array}{c}\text { Change in Values } \\
\text { Post Injection }\end{array}$}} \\
\hline & & Anesthesia & Prolotherapy & Anesthesia & Prolotherapy & & & & \\
\hline & & “[A1]" & "[P1]" & “[A2]" & “[P2]” & $\mathrm{A} 1$ vs $\mathrm{P} 1$ & $\mathrm{~A} 2$ vs $\mathrm{P} 2$ & A1 vs A2 & $\mathrm{P} 1$ vs $\mathrm{P} 2$ \\
\hline $\begin{array}{l}\text { Focal site pain } \\
\text { intensity (1) }\end{array}$ & $0-10$ & $8.5 \pm 1.4$ & $7.9 \pm 1.5$ & $6.2 \pm 2.6$ & $5.8 \pm 2.3$ & NS & NS & 0.0002 & $2 \times 10-5$ \\
\hline Medication intake (2) & $0-2$ & $1.8 \pm 0.6$ & $1.7 \pm 0.6$ & $1.5 \pm 0 . .6$ & $1.7 \pm 0.5$ & NS & NS & NS & NS \\
\hline $\begin{array}{l}\text { Impairment activities } \\
\text { of daily living ( } 3 \text { ) }\end{array}$ & $0-21$ & $10.4 \pm 2.9$ & $10.0 \pm 2.8$ & $9.2 \pm 3.0$ & $9.4 \pm 2.9$ & NS & NS & NS & NS \\
\hline $\begin{array}{l}\text { Impairment work } \\
\text { capacity }(4)\end{array}$ & $0-4$ & $3.3 \pm 0.9$ & $3.0 \pm 0.8$ & $2.4 \pm 1.0$ & $2.5 \pm 1.1$ & NS & NS & 0.0003 & 0.03 \\
\hline $\begin{array}{l}\text { Impairment social } \\
\text { activities (5) }\end{array}$ & $0-4$ & $2.8 \pm 0.9$ & $2.7 \pm 1.0$ & $2.1 \pm 1.1$ & $1.9 \pm 1.2$ & NS & NS & 0.004 & 0.002 \\
\hline
\end{tabular}

Values are Means \pm SD (1) Analog score for pain and tenderness, $10=$ most severe; (2) $0=$ No medication, $1=$ non-narcotic anodynes \&/or NSAID's, $2=$ narcotics (3) $0=$ Normal, $21=$ maximally impaired; (4) $0=$ Normal, $4=$ maximally impaired $(5) 0=$ Normal, $4=$ maximally impaired 
Table 4. Cross-over study of comparative benefit

\begin{tabular}{|l|c|c|c|c|}
\hline \multirow{2}{*}{} & \multicolumn{2}{|c|}{$($ Mean \pm SD) } & \multicolumn{2}{c|}{ (P Values- Wilcoxon Rank Sum Test) } \\
\cline { 2 - 5 } & $\begin{array}{c}\text { Given } \\
\text { First }\end{array}$ & $\begin{array}{c}\text { Given } \\
\text { Second }\end{array}$ & $\begin{array}{c}\text { Benefit From Same } \\
\text { Agent Repeated }\end{array}$ & $\begin{array}{c}\text { Agent Given Second } \\
\text { Compared With First }\end{array}$ \\
\hline Anesthetic & $1.1 \pm 1.2$ & $1.5 \pm 1.3$ & NS & $+4 \times 10-5$ \\
\hline & {$[\mathrm{A} 1]$} & {$[\mathrm{A} 2]$} & {$[\mathrm{A} 1 \mathrm{vs}$ A2] } & {$[$ A1 then P2] } \\
\hline Prolotherapy & $2.3 \pm 1.0$ & $2.5 \pm 0.9$ & NS & -0.004 \\
\hline & {$[\mathrm{P} 1]$} & {$[\mathrm{P} 2]$} & {$[\mathrm{P} 1 \mathrm{vs} \mathrm{P} 2]$} & {$[\mathrm{P} 1$ then A2] } \\
\hline
\end{tabular}

(1) Scale: 0 - 3, with $3=$ greatest benefit

roids into a focal area can cause tissue weakness $(24,27)$. In contrast, one advantage of prolotherapy is its apparent cumulative benefit following repeated administration. Prolotherapy provides sustained pain relief in part by producing tissue toughening through initiating fibroblast and collagen proliferation, which is improved by repeated injections $(2,8,9,12$, $14,17,18,23-29,31,34)$ and also by relatively long-lasting inactivation of small nerve $\mathrm{C}$ fiber transmission produced by hyperosmotic solutions or by phenol and glycerol included in the prolotherapy solution (41). Although other studies have shown that repeated injections of prolotherapy can provide cumulative benefit, this study did not specifically address that aspect of injection therapy. Nonetheless, second injections of each agent did give results which were better (but not statistically significantly so) than results from first injections (Table 4).

Thirty of the 35 patients in this study had been referred to a neurosurgeon because of persistent pain and disability despite prior low back surgery and were referred for consideration for possible additional surgery. After inclusion in this study only four patients subsequently underwent additional surgery, though 29 patients requested repeat injections. This suggests that painful enthesopathies can be major pain generators for some patients and that diagnosing their condition as being due to a focal problem and treating those sites with prolotherapy can be an effective and "minimally invasive" treatment alternative.

\section{CONCLUSION}

This study documents that injection therapy at fibroosseous junctions can provide worthwhile relief of spine pain and tenderness and functional improvement in the short term, even for patients whose pain persists or develops despite prior spine surgery. Phenol-glycerol prolotherapy provides better and longer lasting relief than injection with anesthetics alone. Some patients obtained long-lasting relief, but improvement generally lasted for only a few months; nonetheless the majority of patients graded their relief as "excellent" or "good," reported that the injections had been beneficial to them, and requested additional injections after they left the study, if focal symptoms persisted or recurred.

\section{Author Affiliation:}

Harold A. Wilkinson, MD, PhD

5 Rockridge Rd.

Wellesley Hills, MA 02481-1432

E-mail: hrldawlknsn@aol.com

\section{RefEREnCES}

1. Dorland's Illustrated Medical Dictionary, $30^{\text {th }}$ Edition. WB Saunders Company, Philadelphia, 2003.

2. Bahme B. Observations on the treatment of hypermobile joints by injections. / Am Osteopath Assoc 1945; 45:101-109.

3. Borg-Stein J, Stein S. Trigger points and tender points - One and the same? Does injection treatment help? Rheum Dis Clin N Am 1996; 22:305-321.

4. Boden SD, Wiesel SW. Arthritis and disc disease in the adult: Conservative treatment. In Rothman RH, Simeone FA (eds). The Spine. $2^{\text {nd }}$ Ed. WB Saunders Company, Philadelphia, 1992, pp 591-596.

5. Borenstein DG, Wiesel SW, Boden SD. Low Back Pain: Medical Diagnosis and Comprehensive Management. $2^{\text {nd }}$ Ed. WB Saunders Company, Philadelphia, 1995, pp 602-604.

6. Cherkin DC, Deyo RA, Wheeler K, Ciol MA. Physician views about treating low back pain: The results of a national survey. Spine 1995; 20:1-10.

7. Clark CR. Degenerative conditions of the spine: Differential diagnosis and non-surgical treatment. In Frymoyer JW (ed). The Adult Spine: Principles and Practice. Raven Press, New York, 1991, pp 1581-1605.

8. Dorman T. Diagnosis and Injection Techniques in Orthopedic Medicine. Williams and Wilkins, Baltimore, 1991.

9. Dorman T. Treatment for spinal pain arising in ligaments using prolotherapy: A retrospective study. J Orthop Med 1991; 13: 13-19.

10. Fast A. Low back disorders: conservative management. Arch Phys Med Rehabil 1988; 59:880-891.

11. Finneson BE. Low Back Pain. $2^{\text {nd }}$ Ed. JB Lippincott Company, Philadelphia, 1980, pp 99-100.

12. Garvey TA, Mark MR, Wiesel SW. A prospective, randomized, double-blind evaluation of trigger-point injection therapy for low back pain. Spine 1989; 14:962-964.

13. Haldeman S, Phillips RB. Spinal manipulative therapy in the management of low back pain. In Frymoyer JW (ed). The Adult Spine: Principles and Practice. Raven Press, New York, 1991, pp 1581-1605.

14. Hauser RA. Prolo Your Pain Away. Beulah Land Press, Oak Point, IL, 1998.

15. Ingber RS. Iliopsoas myofascial dysfunction: A treatable cause of "failed" low back syndrome. Arch Phys Med Rehabil 1989; 70:382-386.

16. Kahanovitz N. Diagnosis and Treatment of Low Back Pain. Raven Press, New York, 1991, pp 70-74.

17. Kim M. Myofascial trigger point therapy: Comparison of dextrose, water, saline and lidocaine. Archives Physical Medicine and Rehabilitation 1997; 78:1028.

18. Klein R. A randomized double-blind trial of dextrose-glycerine-phenol injections for chronic low back pain. J Spinal Disord 1993; 6:23-33.

19. Kryzyna NP. The rehabilitation of patients with acute pain in the lumbosacral region. Lik Sprava 1994; (3-4):100-102.

20. Macnab I. Backache. Williams and Wilkins, Baltimore, 1985, pp 80-82.

21. Mennell J. Physical medicine and physical therapy. In Wilkins RH, Rengachary SS (eds). Neurosurgery. McGraw Hill, New York, 1985, pp 2397-2403.

22. Wiltse LL. The history of spinal disorders. In Frymoyer JW (ed). The Adult Spine: Principles and Practice, Raven Press, New York, 1991, pp 3-41.

23. Wilkinson HA, Kwoc KWC. Injection therapy of periosteal trigger points with steroids or prolotherapy. Pain Clin 2002; 4: 40-48.

24. Butler D. Biomechanics of ligaments and tendons. Exerc Sport Sci Rev 1978; 6:125182.

25. Hackett GS, Huang TC, Raftery A, Dodd TJ. Back pain following trauma and disease prolotherapy. Mil Med 1961; 126:517-525.

26. Leedy R. Analysis of 50 low back cases 6 years after treatment by joint ligament sclero- 
therapy. Osteopath Med 1976; 6:15-22.

27. Linetsky FS, Miguel R, Saberski L. Pain management with regenerative injection therapy (RIT). In Weiner RS (ed). Pain Management: A Practical Guide for Clinicians, $6^{\text {th }}$ Ed. CRC Press, Washington, 2001, pp 381-402.

28. Liu Y. An in situ study of the influence of a sclerosing solution in rabbit medial collateral ligaments and its junction strength. Conn Tiss Res 1983; 11:95-102.

29. Mannoril L. Histologic effects of various sclerosing solutions used in the injection treatment of hernia. Arch Surg 1938; 36: 171-189.

30. Nice DA, Riddle DL, Lamb RL, Mayhew TP, Rucker K. Intertester reliability of judgments of the presence of trigger points in patients with low back pain. Arch Phys Med Rehabil 1992; 73:893-898.

31. Ongley M. A new approach to the treatment of chronic low back pain. Lancet 1987; 2:143-146.

32. Rachlin ES. Myofascial Pain and Fibromyalgia: Trigger Point Management. Mosby, St. Louis, 1994.
33. Reeves K. Prolotherapy: Present and future applications in soft-tissue pain and disability. Phys Med Rehabil Clin N Am 1995; 6:917-925.

34. Reeves K. Technique of prolotherapy. In Physiatric Procedures In Clinical Practice. Hanley \& Balfus, Inc., Philadelphia, 1994. pp 57-70.

35. Calabro JJ. Diagnosis of low back pain. In Stanton-Hicks M, Boas R (eds). Chronic Low Back Pain. Raven Press, New York, 1982, pp 39-57.

36. Evans RW. Whiplash injuries. In MacFarlane R, Hardy DG (eds). Outcome After Head, Neck and Spinal Trauma: A Medicolegal Guide. Butterworth-Heinemann, Oxford, England, 1997, pp 359-372.

37. Rosomoff HL, Rosomoff RS. Aggressive nonsurgical management of pain in degenerative disease of the spine. In Menezes AH, Sontag VH (eds). Principles of Spinal Surgery. McGraw Hill, New York, 1985 , pp 645-656.

38. Urban BJ. Diagnostic and therapeutic nerve blocks. In Wilkins RH, Rengachary SS (eds). Neurosurgery. McGraw Hill, New York, 1985, pp 2382-3290.
39. White AH, Anderson R. Conservative Care of Low Back Pain. Williams and Wilkins, Baltimore, 1991, p 24.

40. Wilkinson HA. The Failed Back Syndrome: Etiology and Therapy, $2^{\text {nd }}$ Ed. SpringerVerlag, New York, 1992, pp 144-149.

41. Yahia H. A light and electron microscopic study of spinal ligament innervation. Zeitscr fur Mikroskopische-Anat 1989; 103:664-674.

42. Bagley GP, Bisquier E, Honemann D. Prolotherapy for chronic low back pain - Decision memorandum (\#CAG-00045). Health Care Financing Administration website, Sept. 27, 1999.

43. Loeser JD. Point of View: Prolotherapy injections, saline injections, and exercises for chronic low-back pain. A randomized study. Spine 2003; 29:16.

44. Koop, CE. Preface. In Hauser RA (ed.) Prolo Your Pain Away. Beulah Land Press, Oak Point, IL, 1998.

44. Travel JG, Simons DG. Myofascial Pain and Dysfunction: The Trigger Point Manual. Williams and Wilkins, Baltimore, 1983. 
